\title{
Triiodothyronine-predominant Graves' disease in childhood: detection and therapeutic implications
}

\author{
Julie Harvengt ${ }^{1,+}$, Priscilla Boizeau ${ }^{4,6}$, Didier Chevenne ${ }^{5}$, Delphine Zenaty ${ }^{1}$, \\ Anne Paulsen ${ }^{1}$, Dominique Simon ${ }^{1}$, Sophie Guilmin Crepon ${ }^{1,4,6}$, Corinne Alberti ${ }^{2,4,6}$, \\ Jean-Claude Carel ${ }^{1,2,4}$ and Juliane Léger ${ }^{1,2,3}$ \\ 'Assistance Publique-Hôpitaux de Paris, Service d'Endocrinologie Diabétologie Pédiatrique, Centre de Référence \\ des Maladies Endocriniennes Rares de la Croissance, Hôpital Robert Debré, F-75019 Paris, France, ${ }^{2}$ Université Paris \\ Diderot, Sorbonne Paris Cité, F-75019 Paris, France, ${ }^{3}$ Institut National de la Santé et de la Recherche Médicale \\ (INSERM), Unité 1141, DHU Protect, F-75019 Paris, France, ${ }^{4}$ INSERM, CIC 1426, UMR 1123, Paris, France, \\ ${ }^{5}$ Assistance Publique-Hôpitaux de Paris, Service de Biochimie-Hormonologie and ${ }^{6}$ Assistance Publique-Hôpitaux de \\ Paris, Unité d'Épidémiologie Clinique, Hôpital Robert Debré, Paris, France \\ ${ }^{\dagger}(J$ Harvengt is now at Pediatric Endocrinology Department, CHU de Liége, Bvd de Gaillarmont 600 , \\ 4032 Liége, Belgium)
}

\author{
Correspondence \\ should be addressed \\ to J Harvengt \\ Email \\ Julie.Harvengt@chu.ulg.ac.be
}

\begin{abstract}
Objective: To assess in a pediatric population, the clinical characteristics and management of triiodothyronine-predominant Graves' disease ( $\left.T_{3}-\mathrm{P}-\mathrm{GD}\right)$, a rare condition well known in adults, but not previously described in children.

Design: We conducted a university hospital-based observational study.

Methods: All patients with GD followed for more than 1 year between 2003 and $2013(n=60)$ were included. T3-P-GD (group I) was defined as high free $\mathrm{T}_{3}\left(\mathrm{fT}_{3}\right)$ concentration $(>8.0 \mathrm{pmol} / \mathrm{l})$ associated with a normal free thyroxine $\left(\mathrm{fT}_{4}\right)$ concentration and undetectable TSH more than 1 month after the initiation of antithyroid drug (ATD) treatment. Group II contained patients with classical GD without $\mathrm{T}_{3}-\mathrm{P}-\mathrm{GD}$.

Results: Eight (13\%) of the patients were found to have $T_{3}-P-G D$, a median of $6.3(3.0-10.5)$ months after initial diagnosis $(n=4)$ or 2.8 (2.0-11.9) months after the first relapse after treatment discontinuation $(n=4)$. At GD diagnosis, group I patients were more likely to be younger $(6.8(4.3-11.0)$ vs $10.7(7.2-13.7)$ years) and had more severe disease than group II patients, with higher serum TSH receptor autoantibodies (TRAb) levels: 40 (31-69) vs 17 (8-25) IU/l, $P<0.04$, and with slightly higher serum $\mathrm{fT}_{4}$ (92 (64-99) vs 63 (44-83) pmol/l) and $\mathrm{fT}_{3}(31$ (30-46) vs 25 (17-31) pmol/l) concentrations. During the 3 years following $\mathrm{T}_{3}-\mathrm{P}-\mathrm{GD}$ diagnosis, a double dose of ATD was required and median serum $\mathrm{fT}_{4}: \mathrm{fT}_{3}$ ratio remained lower in group I than in group II.

Conclusion: Severe hyperthyroidism, with particularly high TRAb concentrations at diagnosis, may facilitate the identification of patients requiring regular serum $\mathrm{fT}_{3}$ determinations and potentially needing higher doses of ATD dosage during follow-up.

\section{Introduction}

Graves' disease (GD) is an autoimmune disorder resulting from stimulation of thyrotropin (TSH) receptor by autoantibodies. It is uncommon in children, who account for only $1-5 \%$ of all patients with GD (1). The disease may occur at different ages, but its frequency increases with age, peaking during adolescence (2). Antithyroid drug (c) 2015 European Society of Endocrinology Printed in Great Britain
Published by Bioscientifica Ltd. 
(ATD) treatment is usually recommended as the first-line treatment and is generally well tolerated. The disease seems to be more severe in children than in adults, with a higher overall frequency of relapse, and remission achieved in only $30 \%$ of children, vs $40-60 \%$ of adults, following a first course of treatment lasting about 2 years $(3,4,5,6,7,8,9,10,11)$. We have recently shown that more prolonged medical treatment may increase remission rates to $50 \%$ in children (12).

The clinical diagnosis of GD is generally straightforward and hyperthyroidism is confirmed by high serum free thyroxine ( $\left.\mathrm{fT}_{4}\right)$ and free triiodothyronine $\left(\mathrm{fT}_{3}\right)$ levels, with TSH undetectable in the serum $(<0.05 \mathrm{mIU} / \mathrm{l})$. However, some patients may have high serum $\mathrm{fT}_{3}$ levels with paradoxically normal or even low $\mathrm{fT}_{4}$ levels during the course of the disease. This condition, known as $\mathrm{T}_{3}$-predominant GD ( $\mathrm{T}_{3}$-P-GD) or $\mathrm{T}_{3}$-toxicosis, is well known in adults and may be observed after diagnosis of relapse $(10,13)$. $T_{3}$-P-GD has been shown to be associated with very high titers of serum TSH receptor autoantibodies (TRAb) and large goiters in adults, but its pathogenesis remains unclear (14). Little is known about $\mathrm{T}_{3}$-P-GD in children, but clinical experience suggests that some children with GD can present this form of the disease, making management and treatment difficult. Better characterization of this disorder is required for the improvement of patient management.

The aim of this study was to describe the clinical characteristics and management of $\mathrm{T}_{3}$-P-GD in a pediatric population.

\section{Patients and methods}

\section{Patients}

This observational cohort study included all consecutive patients aged up to 18 years with GD diagnosed and followed for more than 1 year at our department between 2003 and $2013(n=60)$. GD diagnosis was based on clinical signs of hyperthyroidism, combined with TSH concentrations below the detection threshold (TSH $<0.05 \mathrm{mIU} / \mathrm{l}$ ) and high serum $\mathrm{fT}_{4}$ concentration $\left(\mathrm{fT}_{4}>21 \mathrm{pmol} / \mathrm{l}\right.$, normal range $8-21 \mathrm{pmol} / \mathrm{l}$ ) and/or high serum $\mathrm{fT}_{3}$ concentration $\left(\mathrm{fT}_{3}>8.0 \mathrm{pmol} / \mathrm{l}\right.$, normal range $4.4-8.0 \mathrm{pmol} / \mathrm{l}$ ), together with the presence of significant titers of serum TRAb. Neonatal hyperthyroidism was excluded.

$\mathrm{T}_{3}$-P-GD (group I) was defined as high $\mathrm{fT}_{3}$ concentration ( $>8.0 \mathrm{pmol} / \mathrm{l})$ associated with normal $\mathrm{fT}_{4}$ concentration and undetectable TSH during follow-up, more than 1 month after the initiation of ATD treatment $(15,16)$.
All patients without $\mathrm{T}_{3}$-P-GD were assigned to group II. Carbimazole (CMZ) was the ATD used to treat all patients.

\section{Study protocol}

Clinical data of the patients were obtained from their medical records. The following were recorded at GD diagnosis, before the initiation of treatment: age, sex, ethnicity, weight and initial weight loss if any, height, pubertal status, goiter size, presence of tachycardia (pulse rate $>100 / \mathrm{min}$ ), hypertension, presence of ophthalmic abnormalities (exophthalmos and/or upper lid retraction), serum thyroid hormone, TRAb, and thyroid peroxidase autoantibodies (TPOAb) levels. The presence of associated autoimmune disease and a family history of hyperthyroidism (first- and second-degree relatives), if any, were recorded at diagnosis and during follow-up. We then recorded the initial dose and management of ATD treatment during follow-up, total ATD treatment duration, clinical and laboratory tests results, and outcome.

There is currently no evidence that any additional benefit in terms of higher remission rates accrues from the maintenance of high doses of ATD combined with replacement doses of levothyroxine (L- $\left.\mathrm{T}_{4}\right)$ (13). All decisions concerning the management of $\mathrm{L}-\mathrm{T}_{4}$ treatment were therefore made on an individual basis.

Relapse was defined as suppressed TSH levels $(<0.05 \mathrm{mIU} / \mathrm{l})$ combined with serum $\mathrm{fT}_{4}$ concentrations $>21 \mathrm{pmol} / \mathrm{l}$ or $\mathrm{fT}_{3}$ concentrations $>8 \mathrm{pmol} / \mathrm{l}$, after the discontinuation of ATD treatment.

The study protocol was reviewed and approved by the Institutional Review Board of Robert Debre Hospital, Paris 7 University, Assistance Publique-Hôpitaux de Paris. It was explained to all subjects and their parents, who signed a written consent form for participation.

\section{Method}

Height, weight, and BMI (weight/(height) ${ }^{2}$ in $\mathrm{kg} / \mathrm{m}^{2}$ ) were expressed as SDS, to normalize for age and sex $(17,18)$. Pubertal development was assessed by determining Tanner stage. Children were classified as Caucasian or non-Caucasian (African, Asian, and Caribbean) based on the geographic origin of their parents. The size of the thyroid gland was estimated on clinical examination at diagnosis and measured on an ultrasound scan. We corrected for age-related differences in the volume of the normal thyroid gland by classifying into four categories: no goiter, small $(<1.5$ times normal size), moderate 
(1.5-2.5 times normal size), or large ( $>2.5$ times normal size) goiter (8).

Serum TSH, $\mathrm{fT}_{4}$, and $\mathrm{fT}_{3}$ concentrations were determined by competitive immunoassay, using either direct chemiluminescence technology or fluorescence depolarization. TPOAb levels were determined by hemagglutination or RIAs (normal upper limit $10 \mathrm{IU} / \mathrm{l}$ ). TRAb levels were determined with human recombinant $\mathrm{TSH}$ receptors (DYNOtest-Trak human; BRAHMS Diagnostica (Berlin, Germany); normal upper limit 1.5 IU/1).

Reference values for serum $\mathrm{fT}_{4}: \mathrm{fT}_{3}$ ratio were obtained for 125 healthy children without thyroid disease and with a median age of $3.2(1.2-6.1)$ years.

For $\mathrm{T}_{3}-\mathrm{P}-\mathrm{GD}$, the baseline period corresponded to the start of ATD treatment following either the initial diagnosis of GD or the resumption of ATD treatment following disease relapse after the discontinuation of treatment for GD. For presentation of the results, given the nonstandardized timing of follow-up visits, ATD dosages and $\mathrm{fT}_{4}: \mathrm{fT}_{3}$ ratios were grouped by time period as follows: baseline, 1-6, 7-12, 13-24, and 25-36 months from baseline; and TRAb titers as baseline, 1-12 and 13-36 months from baseline.

\section{Statistical analyses}

Results are expressed as numerical values (percentages) for categorical variables, and as medians (25th-75th percentiles) for continuous variables.

For comparisons of the characteristics of different groups of patients, we used $\chi^{2}$ tests for categorical variables and Wilcoxon-Mann-Whitney $U$ tests for continuous variables. There was no adjudication for missing data. Bonferroni's correction for multiple comparisons was applied.

To obtain normative values for children, serum $\mathrm{fT}_{4}: \mathrm{fT}_{3}$ ratio was modeled by the Royston \& Wright parametric method. $Z$-scores were calculated by modeling the mean and s.D. for control subjects, and the 80 and 90\% agespecific reference intervals were defined on the basis of the 10th/90th percentiles and 5th/95th percentiles respectively (19). All analyses were performed with SAS 9.3 Software (SAS Institute, Inc., Cary, NC, USA).

\section{Results}

Eight (13\%) of the patients with GD went on to develop $\mathrm{T}_{3}$-P-GD following treatment with ATD. The cumulative incidence of $\mathrm{T}_{3}$-P-GD increased during the first 3 years of follow-up, to 5\% (95\% CI 2-15\%) at 6 months, 7\% (95\% CI
3-17\%) at 12 months, 8\% (95\% CI 4-19\%) at 24 months, and $16 \%(95 \% \mathrm{CI} 8-30 \%)$ at 36 months (Fig. 1). This condition revealed a median of 10.5 (4.6-28.6) months after diagnosis baseline $(n=8)$, corresponding to a median of $6.3(3.0-10.5)$ months after diagnosis $(n=4)$ or $2.8(2.0-11.9)$ months after the first relapse of the disease $(n=4)$.

The characteristics of the 60 patients at the time of GD diagnosis are given in Table 1 , according to the presence (group I) or absence (group II) of $\mathrm{T}_{3}$-P-GD during the course of the disease. Disease severity was higher in group I than in group II, as demonstrated by the higher serum TRAb levels recorded $(P<0.04)$. The patients in group I tended to be younger and to have higher median serum $\mathrm{fT}_{4}$ and $\mathrm{fT}_{3}$ levels and lower median serum $\mathrm{fT}_{4}: \mathrm{fT}_{3}$ ratios than those in group II, although these differences were not significant. All the patients in group I had medium-sized to large goiters, whereas $21 \%$ of those in group II had only a small goiter or no goiter at all. The two groups of patients were similar in terms of sex ratio, ethnicity, personal history of autoimmunity, and familial history of hyperthyroidism. All patients were initially treated with similar doses of CMZ.

The characteristics of the eight patients (seven girls and one boy) with $\mathrm{T}_{3}$-P-GD are given in Table 2 . The time from $\mathrm{GD}$ diagnosis to $\mathrm{T}_{3}$-P-GD detection ranged from 2.2 to 33.2 months and the median total duration of follow-up until the last evaluation was 4.3 (1.7-6.7) years. All patients with $\mathrm{T}_{3}$-P-GD required an increase in CMZ dose

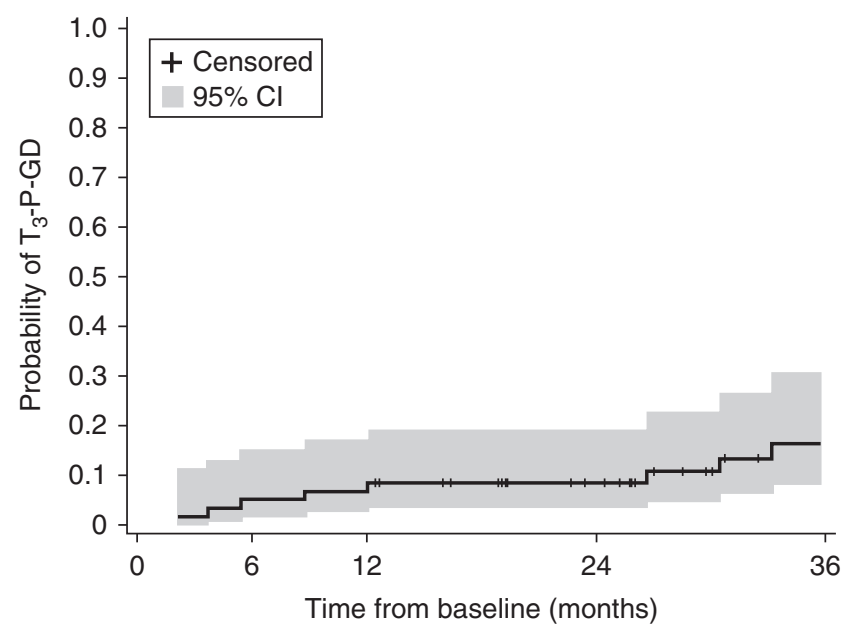

Figure 1

Cumulative incidence of the development of $T_{3}-P-G D$ after diagnosis of GD during childhood, censored at 36 months (inverse Kaplan-Meier graph). 
Table 1 Characteristics at presentation of the children with Graves' disease (GD) seen at a single center between 2003 and 2013 , according to the presence (group I) or absence (group II) of $\mathrm{T}_{3}$-predominant GD. Data are expressed as medians (25th-75th percentiles) or percentages.

\begin{tabular}{|c|c|c|}
\hline & Group I $(n=8)$ & Group II $(n=52)$ \\
\hline Age (years) & 6.8 (4.3 to 11.0$)$ & $10.7(7.2$ to 13.7$)$ \\
\hline \multicolumn{3}{|l|}{ Sex } \\
\hline Female (\%) & 87 & 79 \\
\hline Male (\%) & 13 & 21 \\
\hline \multicolumn{3}{|l|}{ Ethnicity } \\
\hline Caucasian $(\%)$ & 50 & 51 \\
\hline African (\%) & 25 & 27 \\
\hline Asian/Caribbean (\%) & 25 & 20 \\
\hline Weight SDS & $1.16(0.8$ to 3.16$)$ & $0.52(-0.18$ to 1.70$)$ \\
\hline Height SDS & $2.58(1.27$ to 3.53$)$ & 1.23 (0.58 to 2.46$)$ \\
\hline BMI SDS & $-0.17(-0.95$ to 0.53$)$ & $-0.34(-1.29$ to 0.58$)$ \\
\hline \multicolumn{3}{|l|}{ Pubertal development } \\
\hline Prepubertal (Tanner 1) (\%) & 83 & 44 \\
\hline Pubertal (Tanner 2-4) (\%) & 17 & 42 \\
\hline Postpubertal (Tanner 5) (\%) & 0 & 14 \\
\hline Severe initial clinical presentation $(\%)^{a}$ & 75 & 75 \\
\hline Personal history of autoimmunity $(\%)^{b}$ & 13 & 12 \\
\hline Familial history of hyperthyroidism $(\%)^{c}$ & 50 & 23 \\
\hline \multicolumn{3}{|l|}{ Goiter } \\
\hline Absent or small (\%) & 0 & 21 \\
\hline Medium-sized or large (\%) & 100 & 79 \\
\hline $\mathrm{fT}_{4}(\mathrm{pmol} / \mathrm{l})$ & 91.9 (64.0 to 99.0$)$ & 62.8 (44.1 to 83.0$)$ \\
\hline $\mathrm{fT}_{3}(\mathrm{pmol} / \mathrm{l})$ & 30.8 (30.0 to 46.1$)$ & 25.4 (17.4 to 30.8$)$ \\
\hline $\mathrm{fT}_{4}: \mathrm{fT}_{3}$ ratio & $2.1(2.0$ to 2.5$)$ & $2.7(2.2$ to 3.1$)$ \\
\hline TRAb (IU/I) & $40.0(31.2 \text { to } 60.0)^{*}$ & 16.6 (7.7 to 25.3$)$ \\
\hline TPOAb positivity (\%) & 50 & 79 \\
\hline CMZ initial dose (mg/kg per day) & 0.75 (0.67 to 0.82$)$ & $0.70(0.60$ to 0.79$)$ \\
\hline
\end{tabular}

${ }^{*} P=0.04$, group I vs group II. TPOAb, thyroid peroxidase autoantibodies; TRAb, TSH receptor autoantibodies; CMZ, carbimazole.

aSevere initial presentation is characterized by the presence of at least two of the following features: tachycardia, ophthalmic abnormalities, hypertension, and initial weight loss.

${ }^{b}$ In group I, one patient presented type 1 diabetes. In group II, five patients presented type 1 diabetes and one patient had a history of epilepsy.

'First-degree relatives: $n=3$ for group I and $n=7$ for group II. Second-degree relatives: $n=1$ for group I and $n=4$ for group II.

at the time of detection of this condition, to a median of 0.77 (0.71-1.10) $\mathrm{mg} / \mathrm{kg}$ per day. Thyroid function was well controlled for all but one patient (patient 5) at the last evaluation, a median of $3.3(1.3-4.3)$ years after the onset of $\mathrm{T}_{3}$-P-GD. Despite the similar proportion of patients for whom $\mathrm{L}_{-} \mathrm{T}_{4}$ was added to the treatment regimen for various period of time in the two groups (30\% for both groups), the CMZ dose required remained higher in group I than in group II $(P<0.01)$ (Fig. 2). CMZ dose in group I was about twice than that in group II, at $0.62(0.61-0.85)$ vs 0.28 (0.23-0.40) $\mathrm{mg} / \mathrm{kg}$ per day for M7-M12 and $0.46(0.42-$ $0.75)$ vs $0.25(0.17-0.37) \mathrm{mg} / \mathrm{kg}$ per day for M13-M24, following the occurrence of a hyperthyroid state after the diagnosis of GD or a relapse due to treatment discontinuation, for groups I and II respectively. The dose continued to be higher in group I than that in group II in the third year after diagnosis, at $0.43(0.35-0.59)$ vs $0.21(0.13-0.41)$ $\mathrm{mg} / \mathrm{kg}$ per day. Adverse events were minor and transitory and similar numbers of such events occurred in the two groups ( $n=1$ (relative neutropenia) vs $n=3$ ( $n=2$ relative neutropenia and $n=1$ cutaneous rash) for groups I and II respectively).

The patients of group II had serum $\mathrm{fT}_{4}: \mathrm{fT}_{3}$ ratios similar to those of the control group. However, median serum $\mathrm{fT}_{4}: \mathrm{fT}_{3}$ ratios were slightly lower at diagnosis and remained lower in group I than in group II patients, throughout the course of the disease $(P<0.01$; Fig. 3$)$.

Median serum TRAb levels were not determined at all evaluations, but were higher in the patients of group I than in those of group II during the first year following $\mathrm{T}_{3}-\mathrm{P}-\mathrm{GD}$ diagnosis $(P<0.04)$, and similar afterwards (Fig. 4).

\section{Discussion}

The results of this study extend our knowledge about the prevalence and characteristics of $\mathrm{T}_{3}$-P-GD among children with GD. $\mathrm{T}_{3}$-P-GD affected about $10 \%$ of the patients in this cohort of children with GD. As in adults (15), 


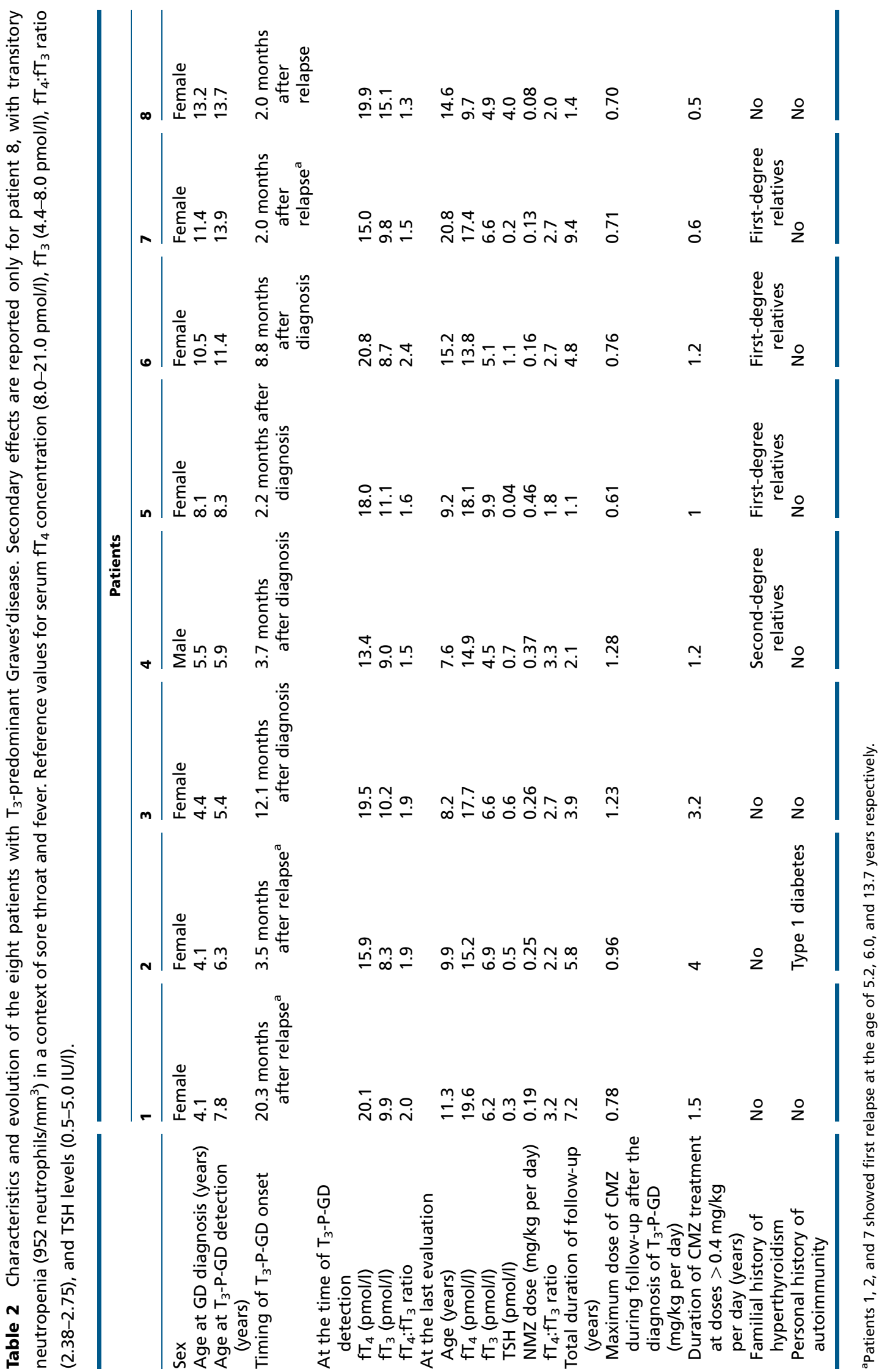




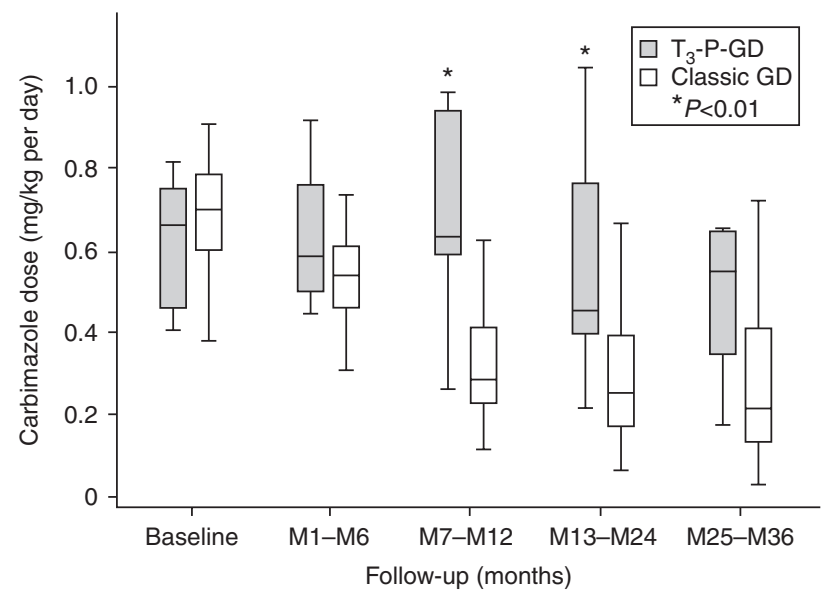

Figure 2

Carbimazole dose at diagnosis and during the course of the disease, expressed for 6-month periods for the first year and then for 12-month periods for the second and third years from baseline, for patients with $T_{3}-P-G D$ and classic GD. Box plots show the median values and the first and third quartiles for each group. T-bars represent the rest of the data, with outliers not shown.

$\mathrm{T}_{3}$-P-GD was observed either a few weeks after diagnosis or after a relapse following the discontinuation of ATD treatment. The timing of $\mathrm{T}_{3}$-P-GD onset was thus highly variable, with this condition occurring 2.2-33.2 months after the diagnosis of GD. As also demonstrated in adults $(16,20), T_{3}$-P-GD was more frequently observed in individuals with larger thyroid glands and higher serum $\mathrm{TRAb}$ levels. The slightly higher serum $\mathrm{fT}_{4}$ and $\mathrm{fT}_{3}$ concentrations and lower $\mathrm{fT}_{4}: \mathrm{fT}_{3}$ ratio at GD diagnosis also demonstrate higher initial disease severity in these patients. Patients with $\mathrm{T}_{3}$-P-GD had median serum $\mathrm{fT}_{4}: \mathrm{fT}_{3}$ ratios that were lower than those of patients with the common form of GD, throughout the course of the disease. These ratios were also significantly lower than those in the control population, for which $\mathrm{fT}_{4}: \mathrm{fT}_{3}$ ratio remained similar throughout childhood. The main consequence for the management of our patients with $\mathrm{T}_{3}$-P-GD was the requirement for higher doses of ATD treatment to maintain satisfactory control over TH levels in affected patients, to keep these levels in the normal range, both during the first few weeks after the onset of $\mathrm{T}_{3}$-P-GD and during the first 2-3 years of treatment, during which the dose required was about twice that for patients with the common form of GD without $T_{3}$-P-GD. By contrast, in a study of adult patients (15), a doubling of the dose of ATD for 1-3 months was not always followed by a normalization of serum $\mathrm{T}_{3}$ levels, such normalization being observed in only two of the six adult patients tested. Furthermore, the normalization of serum $\mathrm{T}_{3}$ levels 2 months after subtotal thyroidectomy in all patients suggested that a radical therapeutic option should be offered rapidly to all patients with $\mathrm{T}_{3}$-P-GD (15). ATD drugs inhibit thyroid hormone synthesis by interfering with the thyroid peroxidase-mediated iodination of the tyrosine residues in thyroglobulin. CMZ and its active metabolite, methimazole, are the recommended pharmacological treatments for hyperthyroidism in children. However, propylthiouracil (PTU) may be of greater benefit in $\mathrm{T}_{3}$-P-GD, as it can also block the conversion of $\mathrm{T}_{4}$ to $\mathrm{T}_{3}$. A switch from methimazole to PTU treatment was tested in a study of adult patients with $\mathrm{T}_{3}$-P-GD, with a positive effect on serum $\mathrm{T}_{3}$ levels after 1 month in only one of the six patients studied (15). However, the use of PTU in children is no longer recommended because of the high risk of PTU-induced severe hepatitis $(21,22)$, therefore none of our patients received PTU as ATD treatment. The frequency of adverse effects has been reported to be dose-related and our patients with $\mathrm{T}_{3}$-P-GD required high doses for a long period of time, but only minor and transitory reactions were observed in few patients, and no severe adverse effects occurred in our

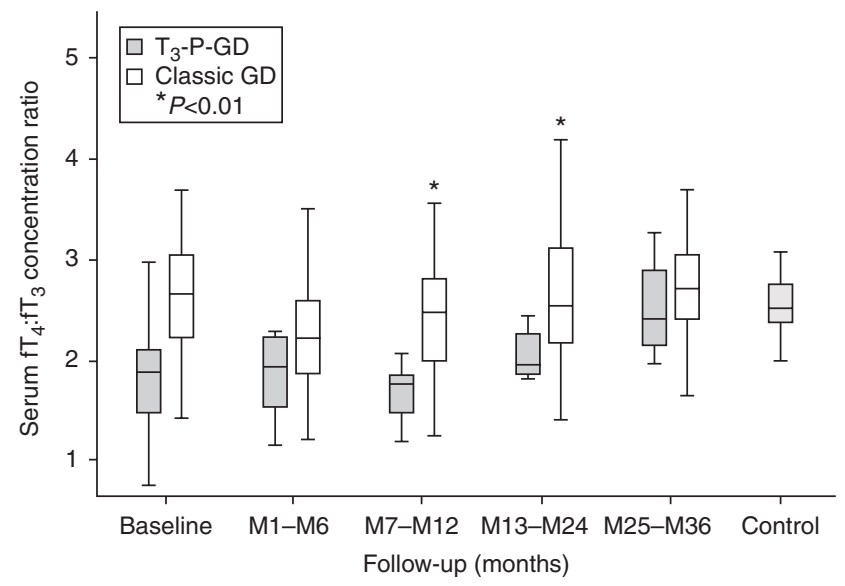

\section{Figure 3}

Ratio of serum $\mathrm{fT}_{4}$ and $\mathrm{fT}_{3}$ concentrations at diagnosis and during the course of the disease, for 6-month periods during the first year and 12-month periods during the second and third years after baseline, in patients with $T_{3}-P-G D$ and classic GD. Box plots show the median values and the first and third quartiles for each group. T-bars represent the rest of the data, with outliers not shown. 


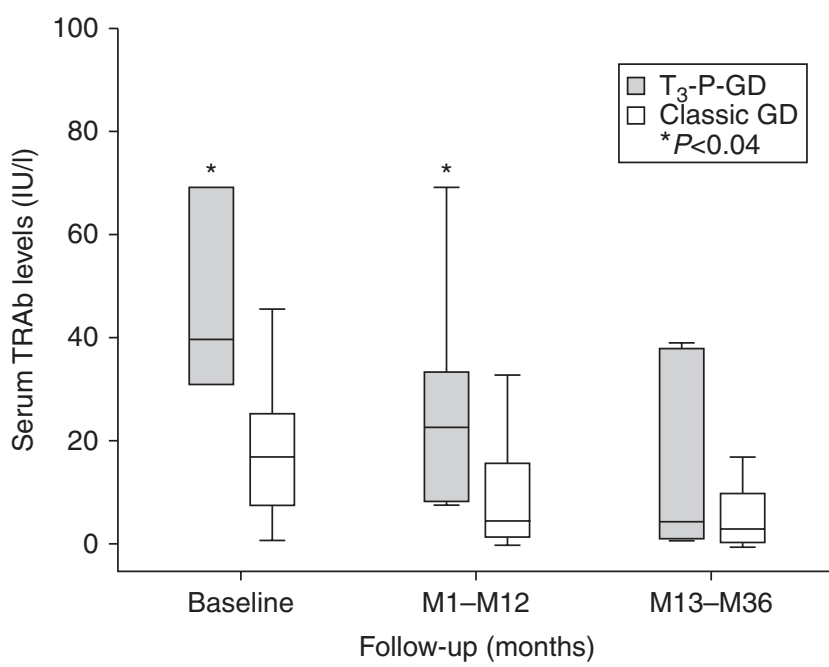

\section{Figure 4}

Median values of TRAb at diagnosis and during the course of the disease, for the first year (M1-M12) and the following 2 years (M13-M36) after baseline. Box plots show the median values and the first and third quartiles for each group. T-bars represent the rest of the data, with outliers not shown.

study population, even in those given maintenance treatment consisting of a high dose of ATD together with replacement doses of $\mathrm{L}_{-} \mathrm{T}_{4}$, regardless of whether they had $\mathrm{T}_{3}$-P-GD or the common type of GD. Moreover, only a limited number of patients received the combination therapy with ATD and $\mathrm{L}-\mathrm{T}_{4}$, for various periods of time and at various doses, with no difference between the two groups. We therefore did not take into account the possibly of exogenous $\mathrm{L}_{-} \mathrm{T}_{4}$ being responsible for the increase in $T_{3}$ levels via $T_{4}$ deiodination due to an increase in type 1 and type 2 iodothyronine deiodinases (DIO1 and DIO2) enzyme activities.

The pathogenesis of $\mathrm{T}_{3}$-P-GD is still not fully understood. High titers of TRAb followed by intense TSH stimulation were thought to underlie the condition and to explain the large goiter observed in affected patients. Current knowledge is not consistent with the hypothesis that high levels of $T_{3}$ production result exclusively from the enhanced conversion of $\mathrm{T}_{4}$ to $\mathrm{T}_{3}$. About $80 \%$ of the circulating $\mathrm{T}_{3}$ is generated by the peripheral deiodination of $\mathrm{T}_{4}$, but the thyroid is also an important source, as $20 \%$ of $\mathrm{T}_{3}$ is secreted by the thyroid gland (23). The molecular mechanism of the disease remains unclear, although DIO1 and DIO2, which catalyze the conversion of $\mathrm{T}_{4}$ to $\mathrm{T}_{3}$ and increase intracellular levels of $\mathrm{T}_{3}$, are known to be overexpressed in the thyroid tissues of patients with
$\mathrm{T}_{3}$-P-GD $(24,25)$, and several genes have recently been shown to be overexpressed in these tissues (26). Given the similarities between thyroid follicular tumors, which contain high levels of DIO1 and DIO2, these data suggest that $\mathrm{T}_{3}$-P-GD may be caused by an increase in the number of differentiated fetal thyroid cells, leading to high levels of proliferation and accounting for the younger age and larger goiter in $\mathrm{T}_{3}$-P-GD patients (23).

Several studies in adults have suggested that the prevalence of $T_{3}$ or $T_{4}$ toxicosis and iodine intake is related, with $\mathrm{T}_{3}$ toxicosis being more prevalent in areas of iodine deficiency $(27,28,29)$. Another hypothesis relates to the selenium status of the patients, which is thought to affect the occurrence of thyroid disease, although this aspect has never been explored in patients with $\mathrm{T}_{3}$-P-GD $(29,30)$.

This is the first study to demonstrate the occurrence of $\mathrm{T}_{3}$-P-GD in children, and one of its major strengths is that all patients diagnosed with GD in a defined population from one clinical center were included. The main limitation of our study was the observational nature of retrospective data collection. Despite the inclusion of all patients with $T_{3}$-P-GD, the number of subjects investigated was small, because this complex condition is very rare, and our study thus provides no further insights into the mechanism underlying severe $\mathrm{T}_{3}$-P-GD.

\section{Conclusion}

These results have important clinical implications. Based on our findings, we identified two groups of children with GD: one group with the classical form of GD and another with $\mathrm{T}_{3}$-P-GD. These findings highlight the need to measure serum $\mathrm{fT}_{3}$ levels and to evaluate $\mathrm{fT}_{4}: \mathrm{fT}_{3}$ ratio in patients with GD, particularly those displaying persistent hyperthyroid symptoms with suppressed serum TSH levels but serum $\mathrm{fT}_{4}$ levels within the normal range. We found that patients with $\mathrm{T}_{3}$-P-GD required doses of ATD twice as high as those used in patients with classic GD, over long periods of time, although it remains unclear why the maintenance of high doses is required. The efficacy of long-term ATD therapy on the occurrence of remission during childhood in affected patients has yet to be studied, but a good approach might be to treat these patients with ATD until they become euthyroid, thereby decreasing the risk of cardiovascular, growth, and skeletal complications. Careful discussion with the parents and the child is then required to determine the best choice of treatment between long-term ATD and more definitive options, such as radioiodine treatment and thyroidectomy, as large 
prospective randomized trials with long-term qualityof-life assessment have not yet been carried out to address this issue in children.

\section{Declaration of interest}

The authors declare that there is no conflict of interest that could be perceived as prejudicing the impartiality of the research reported.

Funding

J Harvengt held a research fellowship from the $\mathrm{CHU}$ of Liège, Belgium.

\section{References}

1 Abraham-Nordling M, Bystrom K, Torring O, Lantz M, Berg G, Calissendorff J, Nystrom HF, Jansson S, Jörneskog G, Karlsson FA et al. Incidence of hyperthyroidism in Sweden. European Journal of Endocrinology 2011165 899-905. (doi:10.1530/EJE-11-0548)

2 Kaguelidou F, Carel JC \& Leger J. Graves' disease in childhood: advances in management with antithyroid drug therapy. Hormone Research 2009 71 310-317. (doi:10.1159/000223414)

3 Zimmerman D \& Gan-Gaisano M. Hyperthyroidism in children and adolescents. Pediatric Clinics of North America 199037 1273-1295.

4 Hamburger JI. Management of hyperthyroidism in children and adolescents. Journal of Clinical Endocrinology and Metabolism 198560 1019-1024. (doi:10.1210/jcem-60-5-1019)

5 Glaser NS \& Styne DM. Predictors of early remission of hyperthyroidism in children. Journal of Clinical Endocrinology and Metabolism 199782 1719-1726.

6 Lazar L, Kalter-Leibovici O, Pertzelan A, Weintrob N, Josefberg Z \& Philip M. Thyrotoxicosis in prepubertal children compared with pubertal and post pubertal patients. Journal of Clinical Endocrinology and Metabolism 200085 3678-3682. (doi:10.1210/jcem.85.10.6922)

7 Barrio R, Lopez Capapé M, Martinez-Badas I, Moreno JC, Carrillo A \& Alonso M. Graves' disease in children and adolescents: response to long-term treatment. Acta Paediatrica 200594 1583-1589. (doi:10.1080/08035250500252872)

8 Glaser NS, Styne DM \& Organization of Pediatric Endocrinologists of Northern California Collaborative Graves' Disease Study Group. Predicting the likelihood of remission in children with Graves' disease: a prospective, multicenter study. Pediatrics 2008121 e481-e488. (doi:10.1542/peds.2007-1535)

9 Kaguelidou F, Alberti C, Castanet M, Guitteny MA, Czernichow P \& Léger J. Predictors of autoimmune hyperthyroidism relapse in children after discontinuation of antithyroid drug treatment. Journal of Clinical Endocrinology and Metabolism 200893 3817-3826. (doi:10.1210/jc. 2008-0842)

10 Franklyn JA \& Boelaert K. Thyrotoxicosis. Lancet 2012379 1155-1166. (doi:10.1016/S0140-6736(11)60782-4)

11 Gastaldi R, Poggi E, Mussa A, Weber G, Vigone MC, Salerno M, Delvecchio M, Peroni E, Pistorio A \& Corrias A. Graves' disease in children: thyroid-stimulating hormone receptor antibodies as remission markers. Journal of Pediatrics 2014164 1189-1194. (doi:10.1016/j. jpeds.2013.12.047)

12 Leger J, Gelwane G, Kaguelidou F, Benmerad M, Alberti C \& French Childhood Graves' Disease Study Group. Positive impact of long-term antithyroid drug treatment on the outcome of children with Graves' disease: national long-term cohort study. Journal of Clinical Endocrinology and Metabolism 201297 110-119. (doi:10.1210/jc. 2011-1944)
13 Bahn RS, Burch HB, Cooper DS, Garber JR, Greenlee MC, Klein I, Laurberg P, McDougall IR, Montori VM, Rivkees SA et al. Hyperthyroidism and other causes of thyrotoxicosis: management guidelines of the American Thyroid Association and American Association of Clinical Endocrinologists. Endocrine Practice 201117 456-520. (doi:10.4158/EP.17.3.456)

14 Laurberg P. Mechanisms governing the relative proportions of thyroxine and 3,5,3'-triiodothyronine in thyroid secretion. Metabolism 198433 379-392. (doi:10.1016/0026-0495(84)90203-8)

15 Takamatsu J, Sugawara M, Kuma K, Kobayashi A, Matsuzuka F, Mozai T $\&$ Hershman JM. Ratio of serum triiodothyronine to thyroxine and the prognosis of triiodothyronine-predominant Graves' disease. Annals of Internal Medicine 1984100 372-375. (doi:10.7326/00034819-100-3-372)

16 Hegedus L, Hansen J, Bech K, Kampmann J, Jensen K, Andersen E, Hansen P, Karstrup S \& Bliddal H. Thyroid stimulating immunoglobulins in Grave's disease with goitre growth, low thyroxine and increasing triiodothyronine during PTU treatment. Acta Endocrinologica $1984107482-488$

17 Sempé M, Pedron G \& Roy-Pernot MP. Auxologie, méthodes et séquences. Paris: Théraplix, 1979. 205 p.

18 Rolland-Cachera MF, Cole TJ, Sempé M, Tichet J, Rossignol C \& Charraud A. Body mass index variations: centiles from birth to 87 years. European Journal of Clinical Nutrition 1991 45 13-21.

19 Royston P \& Wright E. A method for estimating age-specific reference intervals based on fractional polynomials and exponential transformation. Journal of the Royal Statistical Society 1998161 79-101. (doi:10.1111/1467-985X.00091)

20 Chen J \& Ladenson P. Discordant hypothyroxinemia and hypertriiodothyroninemia in treated patients with hyperthyroid Grave's disease. Journal of Clinical Endocrinology and Metabolism 198663 102-106. (doi:10.1210/jcem-63-1-102)

21 Nakamura H, Noh JY, Itoh K, Fukata S, Miyauchi A \& Hamada N. Comparison of methimazole and propylthiouracil in patients with hyperthyroidism caused by Graves' disease. Journal of Clinical Endocrinology and Metabolism 200792 2157-2162. (doi:10.1210/ jc.2006-2135)

22 Williams K, Nayak S, Beker D, Reyes J \& Burmeister L. Fifty years of experience with propylthiouracil-associated hepatotoxicity: what have you learned? Journal of Clinical Endocrinology and Metabolism $1996 \mathbf{8 2}$ 1727-1733.

23 Bianco A, Salvatore D, Gereben B, Berry M \& Larsen P. Biochemistry, cellular and molecular biology, and physiological roles of the iodothyronine selenodeiodinases. Endocrine Reviews 200223 38-89. (doi:10.1210/edrv.23.1.0455)

24 Ito M, Toyoda N, Nomura E, Takamura Y, Amino N, Iwasaka T, Takamatsu J, Miyauchi A \& Nishikawa M. Type 1 and type 2 iodothyronine deiodinases in the thyroid gland of patients with 3-5-3'-triiodothyronine-predominant Graves' disease. European Journal of Endocrinology 2011 164 95-100. (doi:10.1530/ EJE-10-0736)

25 Laurberg P, Vestergaard H, Nielsen S, Christensen S, Seefeldt T, Hellebreg K \& Pedersen KM. Sources of circulating $3,5,3^{\prime}$-triiodothyronine in hyperthyroidism estimated after blocking of type 1 and type 2 iodothyronine deiodinases. Journal of Clinical Endocrinology and Metabolism 200792 2149-2156. (doi:10.1210/ jc.2007-0178)

26 Matsumoto C, Ito M, Yamakawa N, Yoshida H, Date A, Watanabe M, Hidaka Y, Iwatani Y, Miyauchi A \& Takano T. Genes that characterize $\mathrm{T}_{3}$-predominant Graves' thyroid tissues. European Journal of Endocrinology 2013168 137-144. (doi:10.1530/EJE-12-0507)

27 Hollander CS, Mitsuma T, Shenkman L, Stevenson C, Pineda G \& Silva E. $T_{3}$-toxicosis in an iodine-deficient area. Lancet 197216 1276-1278. (doi:10.1016/S0140-6736(72)92650-5)

28 Reinwein D, Benker G, Konig MP, Pinchera A, Schatz H \& Schleusener A. The different types of hyperthyroidism in Europe. 
Results of a prospective survey of 924 patients. Journal of Endocrinological Investigation 198811 193-200. (doi:10.1007/ BF03350134)

29 Carle A, Knudsen N, Pedersen IB, Perrild H, Ovesen L, Rasmussen LB \& Laurberg P. Determinants of serum $\mathrm{T}_{4}$ and $\mathrm{T}_{3}$ at the time of diagnosis in nosological types of thyrotoxicosis: a population-based study.
European Journal of Endocrinology 2013169 537-545. (doi:10.1530/ EJE-13-0533)

30 Pedersen IB, Knudsent N, Carlé A, Schomburg L, Kohrle J, Jorgensen T, Rasmussen LB, Ovesen L \& Laurberg P. Serum selenium is low in newly diagnosed Graves' disease: a population based-study. Clinical Endocrinology 201379 584-590. (doi:10.1111/cen.12185)

Received 6 November 2014

Revised version received 1 March 2015

Accepted 12 March 2015 